\title{
Characterization of Islets from Chronic Calcific Pancreatitis Patients of Tropical Region with Distinct Phenotype
}

\author{
P. Pavan Kumar'1, M. Sasikala1 ${ }^{*}$, K. Mamatha ${ }^{1}$, G. V. Rao², R. Pradeep², R. Talukdar1, \\ D. Nageshwar Reddy ${ }^{1,2}$ \\ ${ }^{1}$ Asian Healthcare Foundation, Hyderabad, India \\ ${ }^{2}$ Asian Institute of Gastroenterology, Hyderabad, India \\ Email: *aigres.mit@gmail.com
}

Received 3 November 2015; accepted 8 January 2016; published 14 January 2016

Copyright @ 2016 by authors and Scientific Research Publishing Inc.

This work is licensed under the Creative Commons Attribution International License (CC BY). http://creativecommons.org/licenses/by/4.0/ c) (i) Open Access

\section{Abstract}

Background and Objective: Islet autotransplantation is performed to preserve endocrine function in patients undergoing pancreatic resections for painful chronic pancreatitis. We characterized islets isolated from chronic pancreatitis patients (CP) of tropical region. Patients and Methods: Pancreatic tissues were obtained from CP patients with and without diabetes undergoing pancreatic resections $(n=35)$ and brain-dead multi organ donors $(n=6$; considered as controls). Islets isolated were assessed for yield, purity, viability and in vitro islet function (Glucose stimulated insulin release, GSIR) as per standard protocols. Results: Islets from CP patients without diabetes were similar to controls in yield (control 4120 - $6100 \mathrm{IE} / \mathrm{g}$, CP 3550 - $5660 \mathrm{IE} / \mathrm{g}$ ), purity (control $78 \% \pm 12 \%, \mathrm{CP} 70 \% \pm 8.2 \%$ ) and viability (control $85 \% \pm 8 \%, \mathrm{CP} 81 \% \pm 10 \%$ ) and islets from $\mathrm{CP}$ patients with diabetes showed decreases in yield (3002 - $2300 \mathrm{IE} / \mathrm{g})$, purity $(61 \% \pm 16 \%)$ and viability $(62 \% \pm 21 \%)$. Islets measuring $50-200 \mu$ were similar in abundance in controls $(94.74 \% \pm$ $3.2 \%$ ) and CP patients with and without diabetes, $86.31 \% \pm 4.9 \%, 91.03 \% \pm 3.8 \%$. GSIR of islets from CP patients and controls were similar at $5.5 \mathrm{mM}$ glucose $(2.8-3.1 \mu \mathrm{U} / \mathrm{ml})$. However, GSIR at $16.5 \mathrm{mM}$ glucose was decreased in CP patients (control $18.5 \pm 0.6$, CP without diabetes $11.8 \pm 0.3$, CP with diabetes $4.3 \pm 0.3 \mu \mathrm{U} / \mathrm{ml}$ ). Conclusion: Our results demonstrate suitability of islets isolated from CP patients of tropical region for autotransplantation.

\section{Keywords}

Islets, Tropical Chronic Pancreatitis, Islet Functions, Transplantation

\footnotetext{
${ }^{*}$ Corresponding author.
}

How to cite this paper: Pavan Kumar, P., Sasikala, M., Mamatha, K., Rao, G.V., Pradeep, R., Talukdar, R. and Reddy, D.N. (2016) Characterization of Islets from Chronic Calcific Pancreatitis Patients of Tropical Region with Distinct Phenotype. Advances in Bioscience and Biotechnology, 7, 1-10. http://dx.doi.org/10.4236/abb.2016.71001 


\section{Introduction}

Islet autotransplantation (IAT) is an accepted treatment option for chronic pancreatitis (CP) patients undergoing pancreatic resections [1]-[12]. Total pancreatectomy followed by islet autotransplantation (TPIAT) is performed in many western countries to relieve intractable pain, preserve endocrine function and improve quality of life in patients with chronic pancreatitis [13], with autografts being more durable than allografts [14]. About one third of the adult patients with CP receiving IAT are insulin independent, with another one third being partially independent and requiring minimal dose of insulin. CP patients who did not achieve insulin independence after IAT had partial graft function and did not experience morbidity due to brittle diabetes [1]. A recent meta analysis of TPIAT by Wu et al. has indicated that islet autotransplantation is safe for CP patients requiring pancreatic resections for pain relief [15]. However, several issues including timing of TPIAT, identification of patients who may benefit from TPIAT, predictable islet isolation outcomes, etc., need to be addressed to improve long term functions of transplanted islets [1] [15]. Despite such limitations, improvements in isolation techniques to increase islet yield for better clinical outcomes have been reported [16].

Prevalence of chronic pancreatitis in South East Asian countries, more so in South India, is comparatively higher (114 - 200/100,000 populations in southern India) than in western countries (10 - 15/100,000) [17]. Presence of large dense pancreatic calculi, ductal dilatation and early onset endocrine dysfunction in nonalcoholic younger generation renders CP a distinct phenotype in India [18]. Etiology of CP in western countries is mainly due to alcohol consumption, while $\approx 60 \%-70 \%$ of CP in India and China are reported to be idiopathic in nature [17]. Though the etiopathogenesis of CP is still not clear, genetic, nutritional and inflammatory factors have been implicated in the disease that leads to abdominal pain, maldigestion and diabetes. Importantly, diabetes in these CP patients is ketosis-resistant, often brittle and difficult to attain normoglycemia with conventional treatment requiring multiple doses of insulin [19].

In pursuit of initiating islet autotransplantation to benefit CP patients from tropical region affected with severe form of the disease at young age, we isolated islets from resected pancreatic tissues obtained from these patients as well as from pancreata obtained from brain dead multi organ donors (MODs; considered as controls) and assessed the suitability for autotransplantation. Our results demonstrate presence of viable islet mass secreting insulin in response to glucose challenge in $\mathrm{CP}$ patients with and without diabetes.

\section{Materials and Methods}

\subsection{Pancreas Procurement and Preservation}

The protocols were approved by the institutional review board and all the patients had given informed consent. Patients with documented CP, as evidenced by pancreatic calcifications on CT scan, ductal or parenchymal abnormalities on secretin stimulated magnetic resonance cholangiopancreatography (MRCP) and histopathological confirmation, and undergoing either lateral pancreaticojejunostomy or distal pancreatectomy or Whipples procedure as a surgical treatment modality were included $(n=310)$. Severity of CP was evaluated on parenchymal assessment by endoscopic ultrasonography (EUS) and ductal morphology by endoscopic retrograde cholangiopancreatography (ERCP). Based on Cambridge classification [20] and histopathological grading of fibrosis [21] [22] patients were categorized either as patients with mild or with severe CP. Based on fasting blood glucose levels CP patients were further categorized into those with and without diabetes. Tissue resected from tail region $(10$ - 20 g) of pancreata $(n=35)$ upon distal pancreatectomy was used for islet isolation and characterization. CP patients below 18 years of age and those with acute exacerbation of chronic pancreatitis, pancreatic cancer and inability to give informed consent were excluded.

Pancreata $(n=6)$ were obtained from brain dead MODs with the consent of the relatives and permission from Jeevan Daan committee located in Hyderabad. Pancreata were retrieved as per standard protocol by the organ retrieval committee while retrieving other organs. Immediately after pancreatic resection the specimen was immersed in cold University of Wisconsin solution and sent to islet isolation facility. Pancreata from brain dead donors were used for standardizing islet isolation for clinical transplantation and comparing islet functions with that obtained from CP pancreata before initiating islet transplantation in CP patients.

\subsection{Islet Isolation}

Islets were isolated from the pancreatic tissue (10 g from tail region) of brain dead MODs as well as from pan- 
creatic specimens resected (10 g, distal pancreatectomy specimens) from CP patients. All the procedures were conducted within the islet isolation facility, established as per cGMP requirements. The pancreatic specimens were cleaned of surrounding fat, muscle, connective tissues and washed thrice with RPMI 1640 nutrient medium.

Islets were isolated from MOD pancreas as per the semi-automated Ricordi isolation method [23]. The main pancreatic duct was cannulated with a 24 gauge catheter and infused with collagenase V solution $(2.5 \mathrm{mg} / \mathrm{gm}$ of pancreas, Sigma/Roche, USA) using a peristaltic pump under recommended conditions of pressure (60 - 180 $\mathrm{mmHg})$, flow rate $(>30 \mathrm{ml} / \mathrm{min})$, temperature $\left(6^{\circ} \mathrm{C}-16^{\circ} \mathrm{C}\right)$ and time $(\sim 15$ minutes). For isolating islets from pancreatic tissue obtained from CP patients, visible ducts in the resected tissue were located and infused with collagenase $\mathrm{V}$ solution ( 2 - $3 \mathrm{mg} / \mathrm{gm}$ of resected pancreas) manually using a needle and 20 cc syringe over a period of 15 minutes. For samples with extensive parenchymal fibrosis and calcifications, interstitial perfusion was performed manually by injecting the enzyme solution in to pancreatic tissue. The tissue was then chopped into small pieces and digested with collagenase V (20 - $25 \mathrm{mg}$ collagenase/10gms pancreas) at $37^{\circ} \mathrm{C}$ for 10 - $30 \mathrm{mi}-$ nutes in a Ricordi chamber; longer periods of incubation were resorted for digestion of severely fibrosed tissue. Progression of digestion was continuously monitored by microscopic examination of aliquots for release of islets by staining with dithizone. When islets were free from acinar tissue, digestion was arrested by dilution and cooling of the enzyme solution with large volumes (4 - $5 \mathrm{~L}$ ) of Hank's solution at $4^{\circ} \mathrm{C}$. The resultant, dispersed pancreatic islets were centrifuged using opti prep based density gradient centrifugation for purification [24]. Isolated islets were assessed for viability and functional efficacy as described below apart from evaluating the sample for its sterility.

\subsection{Histological Examination of Isolated Islets}

Morphological and histological characters of islets within pancreatic tissue from tail region were assessed (before subjecting the tissue for islet isolation) by staining with hematoxylin-eosin, Masson's trichrome and immnuostaining employing standard protocols with minor modifications [25] [26]. In addition, morphological integrity and endocrine cell composition of isolated islets was determined after culturing islets on a cover slip and immnuostaining with guinea pig anti- insulin, mouse anti-glucagon, rabbit anti-somatostatin and rabbit antipancreatic polypeptide antibodies and fluorescent tagged secondary antibodies (goat anti guinea pig alexa 488 for insulin, anti-mousealexa 546 for glucagon, anti-rabbitalexa 546 for somatostatin and pancreatic polypeptide; Santacruz Biotechnologies, USA). All fluorescent images were captured using a CARV II bioimager (BD Bio Sciences, USA).

Islet yield was estimated after isolation by counting dithizone (DTZ)-stained islets in $10 \mu \mathrm{l}$ of homogenous suspension using Olympus microscope (CX41, Tokyo, Japan). Briefly, islets were stained with $10 \mu \mathrm{l} 0.1 \%$ DTZ solution made in Krebs Ringer bicarbonate buffer ( $\mathrm{pH}$ 7.4) containing $10 \mathrm{mM}$ HEPES and incubated at $37^{\circ} \mathrm{C}$ for 10 to $15 \mathrm{~min}$. The stained islets were counted under an inverted microscope (Olympus CX 41; Olympus Corporation, Tokyo, Japan) immediately after isolation and expressed as islet equivalents (IEQ/g). Islet purity was obtained upon counting the relative number of DTZ-stained cells among all the pancreatic cells and expressed as percentage [24].

Islet viability was determined in all the samples using calcein AM, propidium iodide double fluorescence membrane integrity assay to assess the amount of live (green colored) versus dead (red colored) cells [27]. Islets were initially incubated with $0.5 \mathrm{mM}$ calcein-AM at $37^{\circ} \mathrm{C}$ for 45 min following by incubation with $10 \mu \mathrm{l}$ PI (Propidium Iodide) for $15 \mathrm{~min}$ at room temperature in the dark. The stained cells were then washed with PBS and visualized under fluorescent microscope (Olympus CX 41; Olympus Corporation, Tokyo, Japan) attached with digital ProgResC5 cool camera and Capture Pro software (version 2.5).

In Figure 3 the islet size was measured on pancreatic tissue histology. Five blocks per pancreas were prepared from the tail region of each pancreatic specimen. 20 serial sections of $5 \mu$ thickness were sliced from each block. Sections $50 \mu$ apart were used for counting islets. Islet size was measured by capturing islet images in five regions in each section using $4 \mathrm{x}$ objective to count islet numbers. One hundred islets were marked for measuring the islet size using 20x objective. Islet diameter in $\mu \mathrm{m}$ was measured by drawing a line across the islet as mentioned earlier Balamurugan et al., using Olympus microscope employing ProgResC5 cool camera and CapturePro software (version 2.5). Care was taken to avoid measuring same islet. Islets of different sizes (50 - 150 $\mu \mathrm{m}, 150$ - $200 \mu \mathrm{m}$ and $>200 \mu \mathrm{m}$ ) were counted separately and represented in percentages (mean $\pm \mathrm{SD}$ ). 


\subsection{Functional Assessment of Isolated Islets; Glucose Stimulated Insulin Secretion}

Islet equivalents measuring approximately $150 \mu \mathrm{m}$ in diameter $(n=50)$ from controls and CP patients were subjected to static insulin secretory functions on exposure to basal and high glucose concentrations as described earlier [28] following the method by Bottino et al. [29]. Insulin secreted into the medium by isolated islets in response to basal $(5.5 \mathrm{mmol} / \mathrm{L})$ and high $(16.5 \mathrm{mmol} / \mathrm{L})$ glucose stimulation, was measured in triplicates by enzyme-linked immunosorbent assay (Mercodia, Uppsala, Sweden) and reported in terms of micro units of insulin released per minute/islet. Insulin content and islet DNA content were measured once after isolation as recommended [29].

\section{Statistical Analysis}

The data are expressed as mean \pm SD and were analyzed by Analysis of variance (ANOVA). Pair wise comparison was made by Scheffe's test to compare between the groups using SPSS, 20th version. P $<0.05$ was considered significant.

\section{Results}

\subsection{Patient Characteristics}

A total of 41 subjects (35 CP patients and 6 MODs) were included in the study to characterize islet functions. All the CP patients (22 males, age $34.9 \pm 13$ ) showed intra ductal calcifications, dilated ducts and pancreatic atrophy on radiological examination and Inter lobular acinar atrophy, fibro collagenous tissue with intact islets on histopathological examination. Pancreatic specimens obtained from MODs (5 males, age $25 \pm 23$ ) during 2012-2013 were considered as controls in this study. Brain death in the MODs was mainly due to road accidents except for one donor with cardio respiratory failure (female, 30 years). Patients with chronic pancreatitis undergoing pancreatic resections during 2009-2013 $(n=310)$ were considered for this study and 248 of them were diagnosed to have CP with involvement of the main pancreatic duct. Pancreatic tissue from 192 patients undergoing pancreaticojejunostomy and 21 patients undergoing other surgeries were not used for islet isolation. Pancreatic tissue (10 - $20 \mathrm{~g}$, from tail region of the pancreas) was obtained from CP patients undergoing distal pancreatectomy ( $n=35$, Figure 1). Among these, patients with focal lesions on CT scan, parenchymal heterogeneity observed on EUS and intralocular fibrosis were considered to be patients with mild CP $(n=12)$ and all of these patients were non diabetic. Patients with increased ductal wall echoes on CT scan, dilatation, calcifications and calculi in the main pancreatic duct as well as inter-acinar fibrosis were considered to be having severe pancreatitis $(n=23)$. Out of the 35 CP patients included for characterization of islets, 12 patients who had fasting blood glucose $114 \pm 16 \mathrm{mg} / \mathrm{dl}$, decreased C- peptide $0.91 \pm 0.52 \mathrm{ng} / \mathrm{ml}$ and $\mathrm{HbA} 1 \mathrm{C}$ 8.63\% $\pm 1.87 \%$ were diagnosed to have severe CP with diabetes (type3C); the remaining 23 patients with fasting blood glucose $81 \pm 17$ mg/dl, C-peptide $1.6 \pm 0.95 \mathrm{ng} / \mathrm{ml}$ and HbA1C 6.11\% \pm 0.95\% levels were considered to be CP patients without

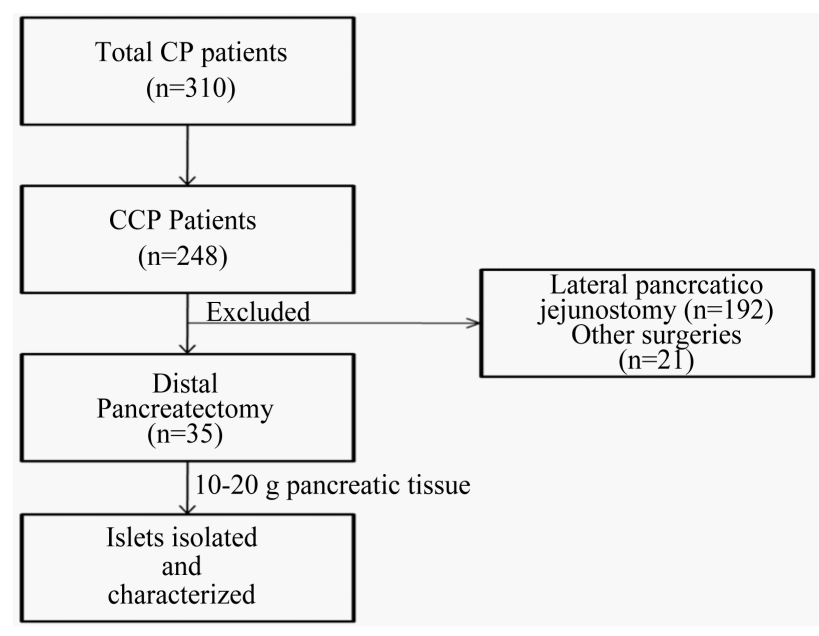

Figure 1. Patient disposition. 
diabetes (mild CP without diabetes 12, severe CP without diabetes 11). Seven out of 12 CP patients with diabetes were treated with insulin and five were treated with oral hypoglycemics.

\subsection{Islet Yield}

Islet yield in CP patients without diabetes was not significantly different (Islets/g $4655 \pm 550$; IEQ/g $5786 \pm 98$ ) in comparison to controls (Islets/g $5186 \pm 885$; IEQ/g $5653 \pm 211$ ). However, the yield was significantly lower (Islets/g $2348 \pm 385$; IEQ/g $2464 \pm 52)$ in CP patients with diabetes $(\mathrm{P}<0.01)$. Purification by density gradient centrifugation resulted inislets with $78 \% \pm 12 \%$ purity in controls, $70 \% \pm 8.2 \%$ in CP patients without diabetes and $61 \% \pm 16.5 \%$ in CP patients with diabetes (Table 1 ).

\subsection{Islet Size}

Measurement of islet size from controls as well as CP patients revealed small (50 - $200 \mu \mathrm{m})$ and large (>200 $\mu \mathrm{m})$ categories of islets. Islets measuring below $50 \mu \mathrm{m}$ were not considered. Islets measuring 50-200 $\mu \mathrm{m}$ were similar in numbers and represented $94.74 \% \pm 3.2 \%$ in controls, $86.31 \% \pm 4.9 \%$ in CP patients with diabetes and $91.03 \% \pm 3.8 \%$ in CP patients without diabetes. However, islets measuring $>200 \mu \mathrm{m}$ were present in higher numbers in CP patients with diabetes $(7.0 \% \pm 2.4 \%)$ and in CP patients without diabetes $(9.08 \% \pm 3.1 \%)$ in comparison to controls $(5.16 \% \pm 1.40 \%)$ as shown in Table 1 .

\subsection{Histological Examination and Islet Viability}

Histological examination and immunostaining of isolated islets showed the presence of $\alpha$ (glucagon + ), $\beta$ (insu$\left.\operatorname{lin}^{+}\right), \delta$ (somatostatin+) and pancreatic polypeptide (PP) secreting cells in the islets isolated from control as well as CP patients with and without diabetes. (Figure 2 panel B). A significant decrease in viability of islets was observed in CP patients with diabetes $(62 \% \pm 21 \%$; P > 0.05$)$ as compared to those without diabetes $(81 \% \pm$ $10 \%)$ and controls $(85.5 \% \pm 8.9 \%)$ as shown in Figure 3.

\subsection{Islet Functions}

Similar to our earlier report on GSIR of islets in CP, Glucose stimulated insulin secretion by the islets from controls, CP patients with and without diabetes was similar at basal glucose concentration (2.8 - $3.1 \mu \mathrm{U} / \mathrm{min} / 50 \mathrm{islet})$. In comparison to controls $(18.5 \pm 0.6 \mu \mathrm{U} / \mathrm{min} / 50$ islet), insulin secretion in response to high glucose in culture

Table 1. Characteristics of islets isolated from control and CP patients.

\begin{tabular}{|c|c|c|c|}
\hline \multirow{2}{*}{ Parameters } & \multirow{2}{*}{ Controls $(n=6)$} & \multicolumn{2}{|c|}{ CP Patients $(n=35)$} \\
\hline & & Without Diabetes $(n=23)$ & With Diabetes $(n=12)$ \\
\hline Islet yield (IEQ/g) & $5653 \pm 211$ & $5786 \pm 98$ & ${ }^{*} 2464 \pm 52$ \\
\hline \multicolumn{4}{|c|}{ Islet size (\% of islets in each category) } \\
\hline $50-100 \mu$ & $21.30 \pm 0.70$ & $16.68 \pm 1.45$ & $16.54 \pm 1.10$ \\
\hline $100-150 \mu$ & $36.24 \pm 1.32$ & $32.63 \pm 3.32$ & $47.36 \pm 1.56$ \\
\hline $150-200 \mu$ & $37.20 \pm 2.83$ & $40.00 \pm 2.65$ & $27.13 \pm 2.30$ \\
\hline$>200 \mu$ & $5.16 \pm 1.40$ & $9.08 \pm 3.10$ & $7.00 \pm 2.40$ \\
\hline Purity \% & $78 \pm 12$ & $70 \pm 8.2$ & $61 \pm 16.5$ \\
\hline Viability\% & $85.5 \% \pm 8.9$ & $81 \pm 10$ & ${ }^{*} 62 \pm 21$ \\
\hline GSIR $\mu \mathrm{U} / \mathrm{ml}$ & $18.5 \pm 0.6$ & $11.8 \pm 0.3$ & $* 4.3 \pm 0.3$ \\
\hline SI & $6.1 \pm 1.4$ & $5.6 \pm 1.0$ & ${ }^{*} 1.8 \pm 1.1$ \\
\hline
\end{tabular}

${ }^{*} \mathrm{P}<0.05$ 

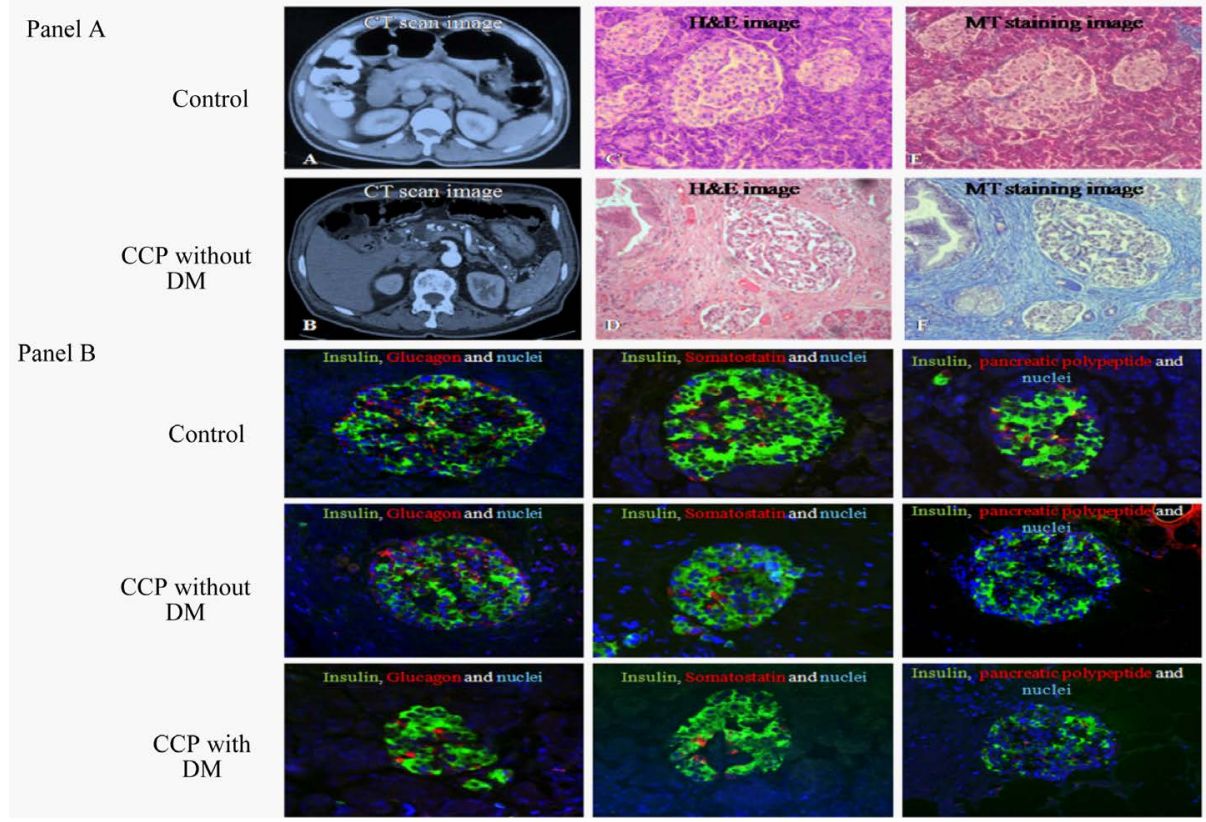

Figure 2. CT scan images and Histological features of islets in control and CP patients. Panel A: Images of MOD (control) with brain injury and calcific chronic pancreatitis patients. (A) CT scan image of control (B) CT scan image of CP patient with calcifications in the main pancreatic duct. Hematoxylin and Eosin (H\&E) staining of tissue sections showing islets (C) acinar tissue and islets in controls (D) islets and peri islet fibrosis in patients with CP. Masson's trichrome (MT) staining in control and CP patient, amidst profound fibrosis (E) \& (F). Panel $\mathrm{B}$ : Immunofluorescent staining of islets from control (upper lane) and CP patients without diabetes (middle lane) and CP patient with diabetes (basaler lane) depicting insulin (green) and glucagon (red), insulin (green) and somatostatin (red) and insulin (green) pancreatic polypeptide (red) secreting cells.

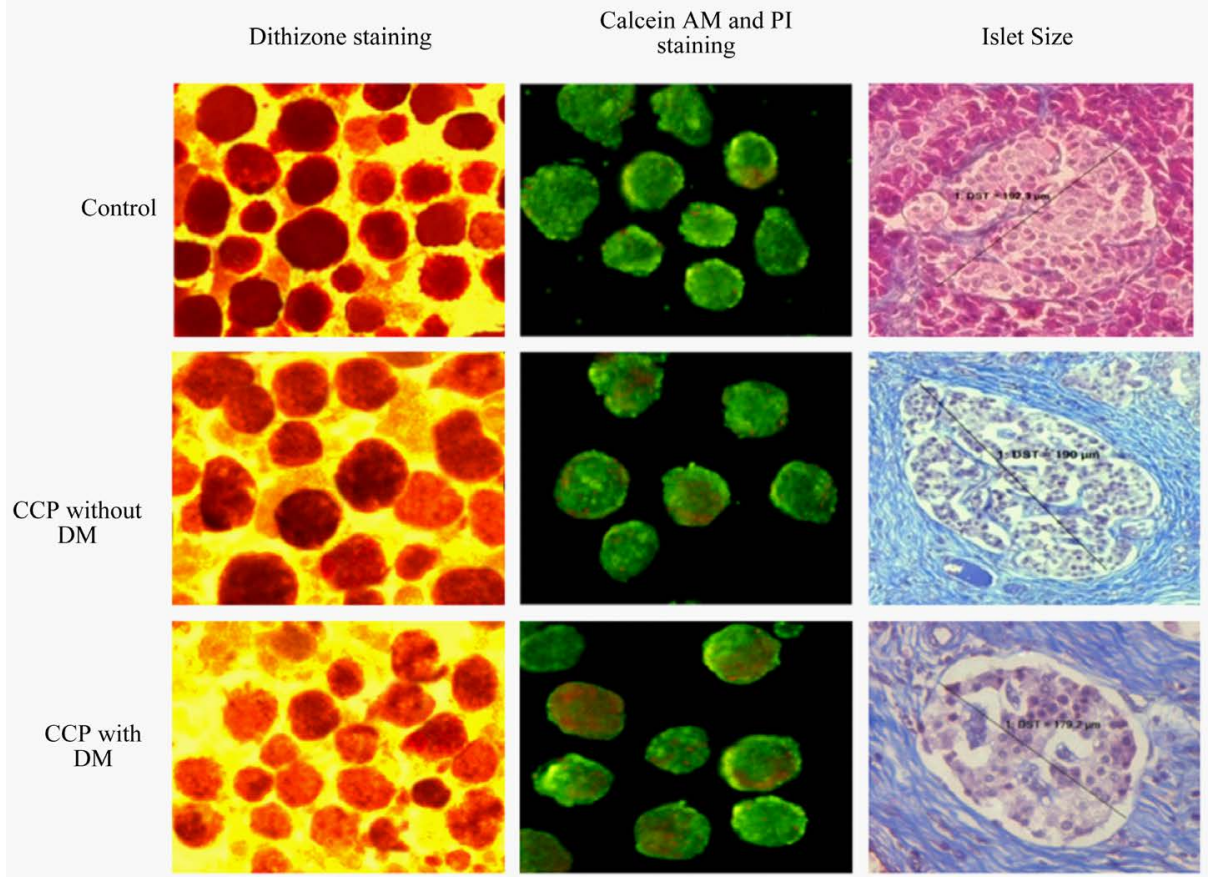

Figure 3. Depicts islets isolated from controls and CP patients with and without diabetes. Islets were stained with dithizone for purity (left column), Calcein AM and propidium iodide for viability (middle column); Green indicates viable mass and red indicates nonviable mass. Viable islets are seen in controls and CP patients although viability is decreased in CP patients with diabetes. Islet size in the three groups is depicted in the last column. 
medium was decreased by islets from CP patients without diabetes $(11.8 \pm 0.3$ in mild and $8.4 \pm 0.5 \mu \mathrm{U} / \mathrm{min} / 50$ islet in severe $\mathrm{CP}$ ). Islets from CP patients with diabetes showed very minimal response to high glucose challenge (4.3 $\pm 0.3 \mu \mathrm{U} / \mathrm{min} / 50$ islet) as shown in Figure 4.

GSIR of islets isolated from control and CP patients with DM and CP patients without DM shows a progressive decrease in GSIR of islets from control to mild, mild to severe and control to CP with diabetes and CP without diabetes to $\mathrm{CP}$ with diabetes. $\mathrm{P}<0.001$

Insulin content for smaller sized islets $(50-150 \mu \mathrm{m})$ was $420 \pm 130 \mu \mathrm{U} / \mathrm{islet}$ in CP and $460 \pm 158 \mu \mathrm{U} /$ islet in controls with the DNA contents being $19 \pm 8 \mathrm{ng}$ /islet in controls and $17 \pm 9 \mathrm{ng} / \mathrm{islet}$ in CP. Stimulation index (SI), as expressed by dividing basal insulin over high glucose insulin release was $6.1 \pm 2.3$ in controls, $5.3 \pm 1.9$ in $\mathrm{CP}$ without diabetes and $1.8 \pm 1.1$ in $\mathrm{CP}$ with diabetes.

\section{Discussion}

Earlier studies have shown the beneficial effects of islet autotransplantation in chronic pancreatitis patients who undergo total/near total/partial pancreatectomy for pain relief. Such attempts are not made in India, wherein the phenotype of CP is distinct and patients present with large ductal stones, severe fibrosis and early onset of diabetes. This study was conducted primarily to characterize the islets isolated from CP patients with and without diabetes. We assessed islet viability, evaluated function of islets, compared with islets isolated from MOD sand demonstrate suitability of islets isolated from CP patients for autotransplantation.

It is well established that glycemic control in islet graft recipients depends upon the islet mass and quality of islets infused. Islet yield obtained in CP patients without diabetes was not significantly different from that of control (Table 1), while the yield was significantly decreased in CP patients with severe pancreatitis. Though the number of islets isolated in CP patients with diabetes was significantly decreased, islets could be isolated even in CP patients with diabetes, which is akin to the observations of a recently published data [30]. In addition, Takita et al. have demonstrated that glycemic control was excellent in both mild and advanced chronic pancreatitis patients who received total pancreatectomy with islet autotransplantation even when the yield was decreased [31]. Researchers at University of Minnesota demonstrated that of the CP patients receiving 2500 - 5000 IEQ/kg, nearly one fifth were insulin independent and one eighth of patients among those receiving $<2500$ IEQ/kg achieved insulin independence at the end of 3 years [1]. The majority of CP patients receiving IAT after pancreatectomy, were shown to have islet graft function (C-peptide positive) and hemoglobin A1C levels in the range of $<7 \%$ [1]. Therefore, islet yield obtained from CP patients with and without diabetes seems to be adequate for use in IAT. However, due caution is to be exercised during islet isolation to clear the calcifications before enzyme infusion into the duct, since the calcifications might cause mechanical injury and loss of function of islets.

The majority of islets in CP patients were between 50 - $200 \mu \mathrm{m}$ in size; $94.74 \% \pm 3.2 \%$ in controls, $86.31 \% \pm$ $4.9 \%$ in CP patients with diabetes and $91.03 \% \pm 3.8 \%$ in CP patients without diabetes, although the number of

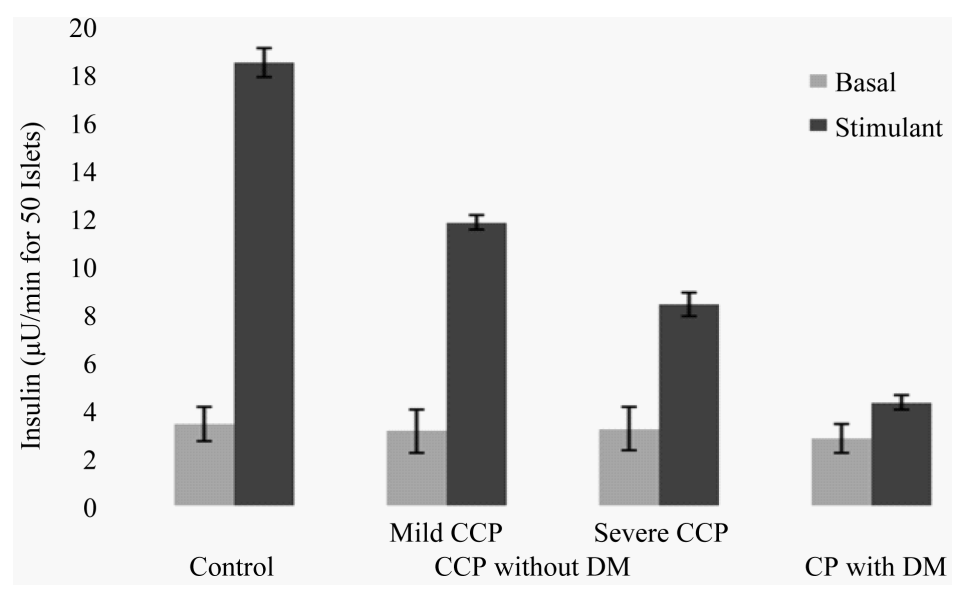

Figure 4. Glucose stimulated insulin secretory function of islets in control and CP patients. 
islets measuring $>200 \mu$ were increased. A study by Suszynski et al. involving 58 CP patients established that those who receive marginal dose of islets were likely to achieve insulin independence if the graft transplanted had greater number of smaller islets [32]. Since smaller islets contribute $80 \%-90 \%$ of the isolate in CP patients, function of the graft could likely be efficient.

Presence of viable islet mass in CP patients with and without diabetes $(62 \% \pm 21 \%$ and $81 \% \pm 10 \%$ respectively) indicated that the islets if transplanted could help stabilize glycemic control. These findings are similar to a proof of concept study which demonstrated that significant islet mass could be isolated from CP patients with c peptide positive diabetes. Even if glycemic control cannot be completely achieved, these studies have demonstrated that $\mathrm{C}$ peptide secreting viable islet mass could at least avoid microvascular complications of diabetes [30]. Islet cluster integrity as evidenced by the presence of $\alpha$ (glucagon + ), $\beta$ (insulin + ), $\delta$ (somatostatin + ) and polypeptide+ cells indicate that the tight coordination of insulin gene expression can be maintained in CP patients.

Glucose stimulated insulin release function of islets from control and CP patients at basal glucose concentration indicate presence of viable mass secreting insulin at basal level. However, decreased response by islets from $\mathrm{CP}$ patients without diabetes and minimal response by islets from CP patients with diabetes at high glucose concentration indicate $\beta$ cell dysfunction. This result is in accordance with our earlier study and could be due to long standing exposure to the inflammatory microenvironment that is prevalent in chronic pancreatitis. HbA1C levels of $6.11 \% \pm 0.95 \%$ in CP patients without diabetes indicate existence of glucose intolerance. Decreased in vitro GSIR ( $\sim 50 \%$ - 60\% of control; Figure 4$)$ by islets from these patients could result in glucose intolerance. This result corroborates with our earlier finding demonstrating $\beta$ cell dysfunction even in non-diabetic CP patients [33]. Gradual decrease in GSIR by islets from controls to CP without diabetes (mild, severe) and to CP with diabetes clearly demonstrates a progressive dysfunction/damage of the islets as the disease progresses. Presence of viable islet mass with a progressive decrease in response to high glucose demonstrates the effect of inflammation on the function of islets. Therefore moving the viable islets from chronic inflammatory milieu to a non inflamed environment before the islets are damaged might improve the high glucose response of the islets from CP patients with and without diabetes. Takita et al. and others have demonstrated that CP patients with preexisting diabetes receiving IAT also maintained good glycemic control [31]. This is probably due to shifting the viable islets from inflamed pancreas to non inflamed environment in the liver. To date there are no data demonstrating permanent damage to the islets in CP. Many investigators also demonstrated that $\mathrm{C}$ peptide positive viable $\beta$ cell mass maintain functions of transplanted islets to the extent that microvascular complications caused by diabetes can be avoided [34]. This study describes the characteristic of islets isolated from CP patients and further studies are focused on assessing the glucose homeostasis in CCP patients after autologous islet transplantation.

\section{Conclusion}

In conclusion, our results demonstrate presence of significant viable and functional islet mass in CP patients with and without diabetes and their suitability for autotransplantation.

\section{Acknowledgements}

The authors are thankful to all the multi organ donor relatives and Jeevan Dhaan committee for consenting to donate pancreas.

\section{References}

[1] Sutherland, D.E., Radosevich, D.M., Bellin, M.D., Hering, B.J., Beilman, G.J., Dunn, T.B., Chinnakotla, S., Vickers, S.M., Bland, B., Balamurugan, A.N., Freeman, M.L. and Pruett. T.L. (2012) Total Pancreatectomy and Islet Autotransplantation for Chronic Pancreatitis. Journal of American College of Surgeons, 214, 409-426. http://dx.doi.org/10.1016/j.jamcollsurg.2011.12.040

[2] Blondet, J.J., Carlson, A.M., Kobayashi, T., Jie, T., Bellin, M., Hering, B.J., Freeman, M.L., Beilman, G.J. and Sutherland, D.E. (2007) The Role of Total Pancreatectomy and Islet Autotransplantation for Chronic Pancreatitis. Surgical Clinics of North America, 87, 1477-1501. http://dx.doi.org/10.1016/j.suc.2007.08.014

[3] Bellin, M.D. and Sutherland. D.E. (2010) Pediatric Islet Autotransplantation: Indication, Technique, and Outcome. Current Diabetes Reports, 10, 326-331. http://dx.doi.org/10.1007/s11892-010-0140-4 
[4] Clayton, H.A., Davies, J.E., Pollard, C.A., White, S.A., Musto, P.P. and Dennison, A.R. (2003) Pancreatectomy with Islet Autotransplantation for the Treatment of Severe Chronic Pancreatitis: The First 40 Patients at the Leicester General Hospital. Transplantation, 76, 92-98. http://dx.doi.org/10.1097/01.TP.0000054618.03927.70

[5] Garcea, G., Weaver, J., Phillips, J., Pollard, C.A., Ilouz, S.C., Webb, M.A., Berry, D.P. and Dennison, A.R. (2009) Total Pancreatectomy with and without Islet Cell Transplantation for Chronic Pancreatitis: A Series of 85 Consecutive Patients. Pancreas, 38, 1-7. http://dx.doi.org/10.1097/MPA.0b013e3181825c00

[6] Morgan, K., Owczarski, S.M., Borckardt, J., Madan, A., Nishimura, M. and Adams, D.B. (2012) Pain Control and Quality of Life after Pancreatectomy with Islet Autotransplantation for Chronic Pancreatitis. Journal of Gastrointestinal Surgery, 16, 129-134. http://dx.doi.org/10.1007/s11605-011-1744-y

[7] Cameron, J.L., Mehigan, D.G., Broe, P.J. and Zuidema, G.D. (1981) Distal Pancreatectomy and Islet Autotransplantation for Chronic Pancreatitis. Annals of Surgery, 193, 312-317. http://dx.doi.org/10.1097/00000658-198103000-00010

[8] Takita, M., Naziruddin, B., Matsumoto, S., Noguchi, H., Shimoda, M., Chujo, D., Itoh, T., Sugimoto, K., Onaca, N., Lamont, J.P., Lara, L.F. and Levy, M.F. (2010) Variables Associated with Islet Yield in Autologous Islet Cell Transplantation for Chronic Pancreatitis. Proceedings (Baylor University. Medical Center), 23, 115-120.

[9] Argo, J.L., Contreras, J.L., Wesley, M.M. and Christein, J.D. (2008) Pancreatic Resection with Islet Cell Autotransplant for the Treatment of Severe Chronic Pancreatitis. American Journal of Surgery, 74, 530-536.

[10] Berney, T., Rüdisühli, T., Oberholzer, J., Caulfield, A. and Morel, P. (2000) Long-Term Metabolic Results after Pancreatic Resection for Severe Chronic Pancreatitis. American Board of Surgery, 135, 1106-1111.

[11] Dixon, J., DeLegge, M., Morgan, K.A. and Adams, D.B. (2008) Impact of Total Pancreatectomy with Islet Cell Transplant on Chronic Pancreatitis Management at a Disease-Based Center. American Journal of Surgery, 74, 735-738.

[12] Ahmad, S.A., Lowy, A.M., Wray, C.J., D’Alessio, D., Choe, K.A., James, L.E., Gelrud, A., Matthews, J.B. and Rilo, H.L. (2005) Factors Associated with Insulin and Narcotic Independence after Islet Autotransplantation in Patients with Severe Chronic Pancreatitis. Journal of the American College of Surgeons, 201, 680-607.

[13] Drewes, A.M. (2013) Understanding and Treatment of Chronic Pancreatitis. World Journal of Gastroenterology, 14, 7219-7221. http://dx.doi.org/10.3748/wjg.v19.i42.7219

[14] Sutherland, D.E., Gruessner, A.C., Carlson, A.M., Blondet, J.J., Balamurugan, A.N., Reigstad, K.F., Beilman, G.J., Bellin, M.D. and Hering, B.J. (2008) Islet Autotransplant Outcomes after Total Pancreatectomy: A Contrast to Islet Allograft Outcomes. Transplantation, 27, 1799-1802. http://dx.doi.org/10.1097/TP.0b013e31819143ec

[15] Wu, Q., Zhang, M., Qin, Y., Jiang, R., Chen, H., Xu, X., Yang, T., Jiang, K. and Miao, Y. (2015) Systematic Review and Meta-Analysis of Islet Autotransplantation after Total Pancreatectomy in Chronic Pancreatitis Patients. Endocrine Journal, 62, 227-234. http://dx.doi.org/10.1507/endocrj.EJ14-0510

[16] Balamurugan, A.N., Bellin, M.D. and Papas, K. (2011) Maximizing Islet Yield from Pancreata with Chronic Pancreatitis for Use in Islet Auto-Transplantation Requires a Modified Strategy from Islet Allograft Preparations. Pancreas, 40, 1312.

[17] Braganza, J.M., Lee, S.H., McCloy, R.F. and McMahon, M.J. (2011) Chronic Pancreatitis. The Lancet, 377, $1184-1197$. http://dx.doi.org/10.1016/S0140-6736(10)61852-1

[18] Balakrishnan, V. and Rajesh, G. (2012) Chronic Pancreatitis: A South India Perspective. Medicine Update, 22, 445449.

[19] Unnikrishnan, R. and Mohan, V. (2015) Fibrocalculous Pancreatic Diabetes (FCPD). Acta Diabetologica, 52, 1-9. http://dx.doi.org/10.1007/s00592-014-0685-9

[20] Ahmed, S.A., Wray, C., Rilo, H.L., Choe, K.A., Gelrud, A., Howington, J.A., Lowy, A.M. and Matthews, J.B. (2006) Chronic Pancreatitis: Recent Advances and Ongoing Challenges. Current Problems in Surgery, 43, 127-238. http://dx.doi.org/10.1067/j.cpsurg.2005.12.005

[21] Ammann, R.W., Heitz, P.U. and Klöppel, G. (1996) Course of Alcoholic Chronic Pancreatitis: A Prospective Clinicomorphological Long-Term Study. Gastroenterology, 111, 224-231. http://dx.doi.org/10.1053/gast.1996.v111.pm8698203

[22] Chong, A.K., Hawes, R.H., Hoffman, B.J., Adams, D.B., Lewin, D.N. and Romagnuolo, J. (2007) Diagnostic Performance of EUS for Chronic Pancreatitis: A Comparison with Histopathology. Gastrointestinal Endoscopy, 65, 808-814. http://dx.doi.org/10.1016/j.gie.2006.09.026

[23] Ricordi, C., Lacy, P.E. and Scharp, D.W. (1989) Automated Islet Isolation from Human Pancreas. Diabetes, 38, 140142. http://dx.doi.org/10.2337/diab.38.1.S140

[24] Latif, Z.A., Noel, J. and Alejandro, R. (1988) A Simple Method of Staining Fresh and Cultured Islets. Transplantation, 45, 827- 830. http://dx.doi.org/10.1097/00007890-198804000-00038

[25] Bancroft, J. and Stevens, A. (1982) Theory and Practice of Histological Techniques. 2nd Edition, Churchill Living- 
stone, New York, 131-135.

[26] Balamurugan, A.N., Chang, Y., Fung, J.J., Trucco, M. and Bottino, R. (2003) Flexible Management of Enzymatic Digestion Improves Human Islet Isolation Outcome from Sub-Optimal Donor Pancreata. American Journal of Transplantation, 3, 1135-1142. http://dx.doi.org/10.1046/j.1600-6143.2003.00184.x

[27] Lorenzo, A., Razzaboni, B., Weir, G.C. and Yankner, B.A. (1994) Pancreatic Islet Cell Toxicity of Amylin Associated with Type-2 Diabetes Mellitus. Nature, 21, 756-760. http://dx.doi.org/10.1038/368756a0

[28] Mitnala, S., Pondugala, P.K., Guduru, V.R., Rabella, P., Thiyyari, J., Chivukula, S., Boddualli, S., Hardikar, A.A. and Reddy, D.N. (2010) Reduced Expression of PDX-1 Is Associated with Decreased Beta Cell Function in Chronic Pancreatitis. Pancreas, 39, 856-862. http://dx.doi.org/10.1097/MPA.0b013e3181d6bc69

[29] Bottino, R., Balamurugan, A.N., Bertera, S., Pietropaolo, M., Trucco, M. and Piganelli, J.D. (2002) Preservation of Human Islet Cell Functional Mass by Anti-Oxidative Action of a Novel SOD Mimic Compound. Diabetes, 51, 25612567. http://dx.doi.org/10.2337/diabetes.51.8.2561

[30] Bellin, M.D., Beilman, G.J., Dunn, T.B., Pruett, T.L., Chinnakotla, S., Wilhelm, J.J., Ngo, A., Radosevich, D.M., Freeman, M.L., Schwarzenberg, S.J., Balamurugan, A.N., Hering, B.J. and Sutherland, D.E. (2013) Islet Autotransplantation to Preserve Beta Cell Mass in Selected Patients with Chronic Pancreatitis and Diabetes Mellitus Undergoing Total Pancreatectomy. Pancreas, 42, 317-321. http://dx.doi.org/10.1097/MPA.0b013e3182681182

[31] Takita, M., Naziruddin, B., Matsumoto, S., Noguchi, H., Shimoda, M., Chujo, D., Itoh, T., Sugimoto, K., Onaca, N., Lamont, J., Lara, L.F. and Levy, M.F. (2011) Implication of Pancreatic Image Findings in Total Pancreatectomy with Islet Autotransplantation for Chronic Pancreatitis. Pancreas, 40, 103-108. http://dx.doi.org/10.1097/MPA.0b013e3181f749bc

[32] Suszynski, T.M., Wilhelm, J.J., Radosevich, D.M., Balamurugan, A.N., Sutherland, D.E., Beilman, G.J., Dunn, T.B., Chinnakotla, S., Pruett, T.L., Vickers, S.M., Hering, B.J., Papas, K.K. and Bellin, M.D. (2014) Islet Size Index as a Predictor of Outcomes in Clinical Islet Autotransplantation. Transplantation, 27, 1286-1291. http://dx.doi.org/10.1097/01.TP.0000441873.35383.1e

[33] Sasikala, M., Talukdar, R., Pavan Kumar, P., Radhika, G., Rao, G.V., Pradeep, R., Subramanyam, C. and Nageshwar Reddy, D. (2012) $\beta$-Cell Dysfunction in Chronic Pancreatitis. Digestive Diseases and Science, 57, 1764-1772. http://dx.doi.org/10.1007/s10620-012-2086-7

[34] Ali, M.A. and Dayan, C.M. (2009) The Importance of Residual Endogenous Beta Cell Preservation in Type 1 Diabetes. British Journal of Diabetes and Vascular Diseases, 9, 248-253. 